\title{
A method of restraining goldfish during conditioning of electric-shock-induced suppression of breathing movements
}

\author{
ROGER E. DAVIS \\ Mental Health Research Institute, University of Michigan, Ann Arbor, Michigan 48109
}

\begin{abstract}
An efficient method of holding individual fish in position for delivery of visual conditioned stimuli and electrical unconditioned stimuli, and for registration of breathing movements with a thermistor, is described. The holder restrains the fish gently and is readily opened and closed. In addition, a "mechanical fish" signal generator, for assessing thermistor performance in detecting breathing movements, and a safe constant-current electrical shock stimulus generator are described.
\end{abstract}

Pavlovian, or classical conditioning, is used in investigations of learning (Overmier \& Curnow, 1969; Overmier \& Savage, 1974) and sensory processes in fish (Northmore \& Yager, 1975; Powers \& Easter, 1978; Yager \& Sharma, 1975). In experiments on optic nerve regeneration in the goldfish, Carassius auratus, in our laboratory, the rate of regeneration is assessed by measuring the time to recovery of a conditioned response to a visual stimulus. The regenerating optic nerve is a promising preparation for screening chemical substances for toxic effects on developing neurons (Davis \& Benloucif, in press). The response consists of a suppression of breathing movements during the first $5 \mathrm{sec}$ of a $15 . \mathrm{sec}$ presentation of the visual stimulus, which is conditioned by pairing the visual stimulus with a noxious electrical shock to the fish's body.

A problem in conditioning fish is how to physically restrain the subject during conditioning trials. Restraint is necessary to facilitate stimulus presentation and response recording. In goldfish, gentle or loose restraint is desirable. Firm restraint, as produced, for example, by clamping the body between foam pads, can injure the skin and interfere with the subjects' attention to the conditioned stimulus. The restraining device, or fish holder, should also be simple to operate and to maintain. This report describes a convenient fish holder which resembles a book. The holder is designed for visual conditioning in goldfish using electrical shock reinforcement and respiratory suppression as the conditioned response. With appropriate modification, however, the holder could also serve in conditioning auditory or olfactory stimuli, and virtually any species of fish that tolerates such confinement could be used.

The holder consists of a three-layered sandwich of opaque, black Plexiglas that is $2.5 \mathrm{~cm}$ thick, $12.5 \mathrm{~cm}$ high, and $17.5 \mathrm{~cm}$ long (Figures 1 and 2). A cavity cut

This research was supported by United States Environmental Protection Agency Grant R808064.



Figure 1. Fish holder with the hinged side opened showing a goldfish in the compartment.

out of the middle layer forms the fish compartment. The middle is twice the thickness of the two outer layers. Holes $6.2 \mathrm{~mm}$ in diameter drilled in the center line of the middle layer penetrate the fish compartment from the top and both ends. The holes provide openings for (1) the thermistor probe that is used to detect breathing movements (Northmore \& Yager, 1975), (2) the release of air bubbles, (3) drainage of feces when the holder is raised from the water, and (4) the "mechanical fish" signal generator (Figure 2).

One outer layer is attached to the middle with stainless steel machine screws to enable periodic replacement of the transparent, perforated polyethylene membrane (pm) that forms the sidewall of the fish compartment. The 4-mm perforations facilitate water circulation and delivery of the electric shock stimulus. The membrane is attached to the inner surface of the outer layer with waterproof tape (Figure 1). The other outer layer is 

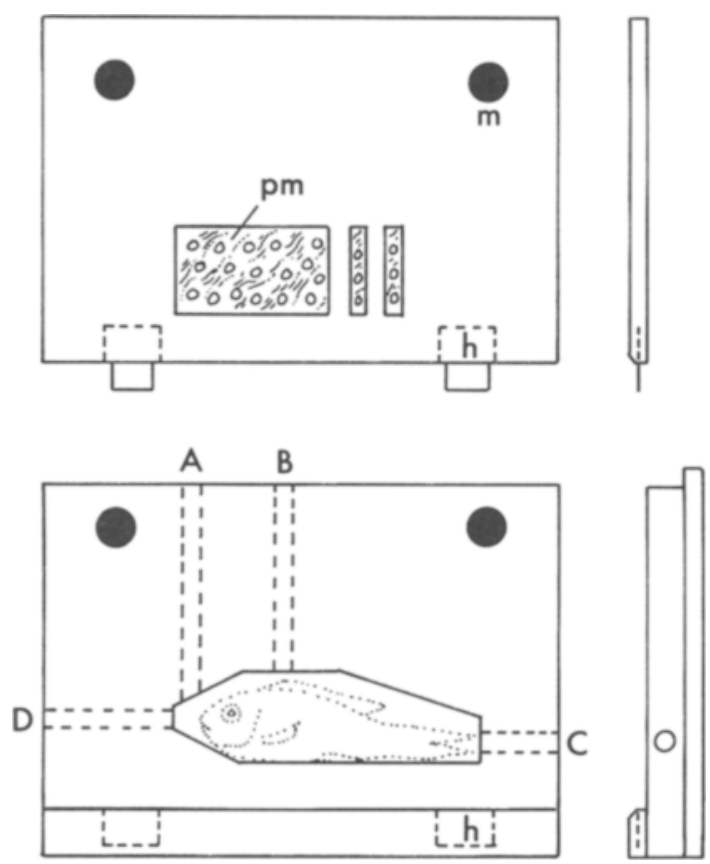

Figure 2. Side and end views of the fish holder with the hinged layer (upper figure) removed to show the opening in the middle layer, which forms the fish compartment. The abbreviations are explained in the text.

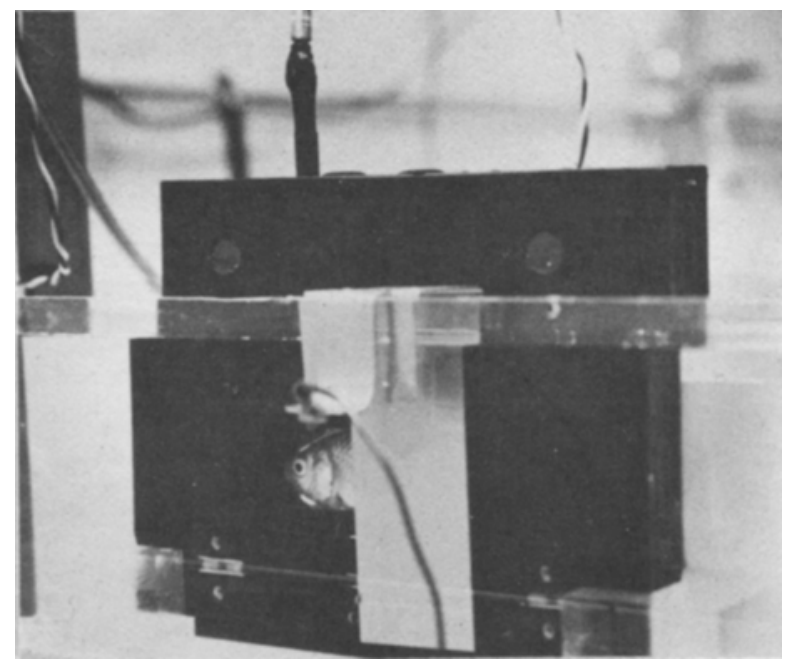

Figure 3. Fish holder in a conditioning tank. One of the two electrodes used to deliver the electric shock stimulus is shown positioned alongside the caudal half of the fish's body.

hinged and held closed with carbon magnets $(\mathrm{m})$. The hinges $(\mathrm{h})$ are plastic tongue-and-pocket model-airplane aileron hinges (Robart Manufacturing). The tongue is locked in place with a stainless steel set screw. Three hinges were used in a prototype (Figure 1), but two will do (Figure 2).

In operation, fish brought from the home tank room to the experiment room in individual containers are transferred by hand to individual holders. The holders are stacked flat on a table so that the hinged side can be opened and closed with one hand and the other hand is left free to manipulate the fish. Each holder is placed in a separate tank (Figure 3). At the end of the conditioning session, the holder is lifted from the tank and opened to drop the fish into its transportation container.

\section{THERMISTOR PROBE}

The thermistor (Fenwall GB 32J2) is embedded in waterproof epoxy (e.g., Miller-Stephenson Chemical Company) or silicone rubber (e.g., Dow Corning) in a 6-mm-OD glass tube. After placing the fish holder in the tank, the thermistor probe is inserted in the hole that penetrates the head end of the fish compartment (Figure 4). A Buna rubber O-ring (Small Parts, Inc.) retains the probe so that the thermistor is flush with the opening in the compartment. If the probe penetrates the compartment, fish lunging forward during shock stimulation can receive skin-damaging blows on the roof of the cranium. When the holder is to be removed from the tank, the probe is withdrawn and suspended in a container of water to protect the tip.

\section{MECHANICAL FISH SIGNAL GENERATOR}

A standard signal simulating that produced by a fish's breathing movements is useful for measuring the relative sensitivity of newly prepared thermistor probes and for detecting changes that occur with time in service. A

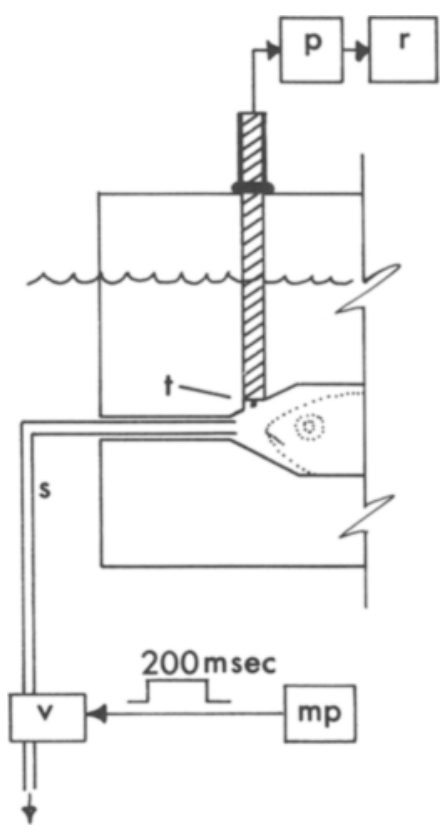

Figure 4. Diagram of the front half of the fish holder showing the location of the thermistor ( $t$ ) at the tip of the probe and the position of the siphon tube (s) and valve (v) that is used to generate the mechanical fish signal. A microprocessor (mp) operates the valve. The head stage preamplifier $(p)$ is used to lower the impedance of the thermistor output for transmission to the recording system ( $r$ ) in a nearby room. 


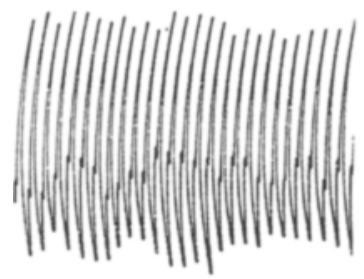

GOLDFISH

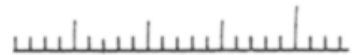

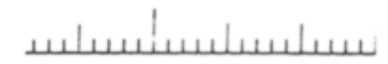

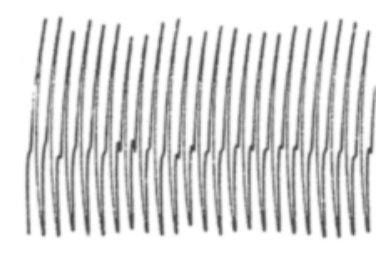

MECHANICAL FISH

\section{Seconds}

Figure 5. Example polygraph recordings of the breathing movement of goldfish and of the water movements produced by the "mechanical fish" generator.

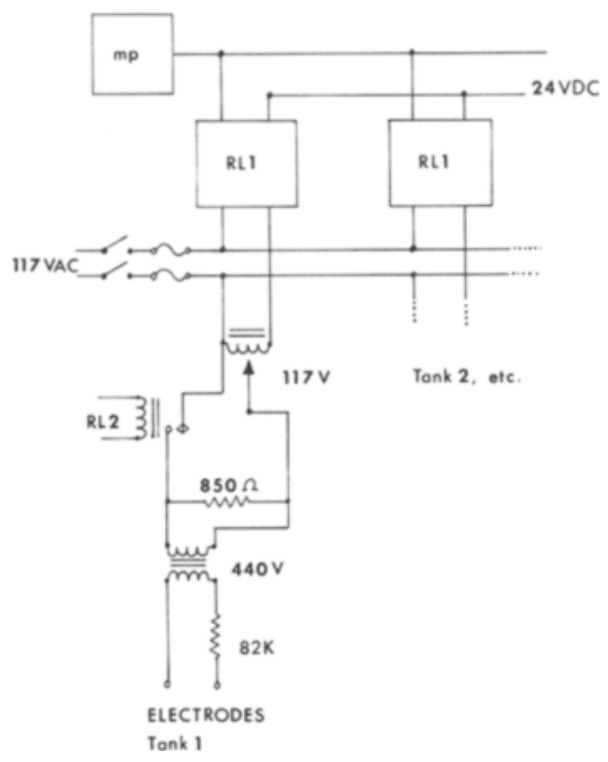

Figure 6. Diagram of the constant-current shock generator.

signal resembling that of a goldfish (Figure 5) is produced by a siphon tube which draws water from the head end of the fish compartment (Figure 4). The siphon is regulated by a solenoid valve (Skinner Valve, V 52DA2200). To determine whether a thermistor is operating satisfactorily, the tip of the siphon tube is inserted into hole $\mathrm{D}$, then the valve is opened momentarily (e.g., $200 \mathrm{msec}$ ) once a second, and the output of the thermistor is evaluated in relation to its past performance or to the performance of other probes.

\section{ELECTRIC SHOCK GENERATOR}

In our experiments, conditioning trials are administered simultaneously in every tank or in one tank only. To obtain a constant-current stimulus, each tank is provided with its own shock generator (Figure 6). The duration of the shock is regulated by the microproces- sor, which controls the $24-\mathrm{V}$ dc solid state relay, RL1 (Crydom 1210), and the mercury relay, RL2 (Clare HGWM 5111T00). Shock intensity is set by adjusting the $117-\mathrm{V}$ ac variable transformer. The $440-\mathrm{V}$ ac step-up transformer provides the necessary voltage and effectively isolates the electrodes from ground, thereby reducing the shock hazard to the investigator. Relay $\mathrm{R} 1$ contains a transient suppression circuit that results in a minute current flow while the relay is nominally open. Relay R2 serves to block this current during the intershock interval. The electrodes we use are made of flexible, flat-stock stainless steel, which is easily shaped to form a vertical plate paralleling the side of the fish holder (Figure 3).

\section{FISH COMPARTMENT DIMENSIONS}

The size and shape of the fish compartment were determined by trial and error to condition fish ranging from approximately 8 to $13 \mathrm{~cm}$ from the body length. To keep the smaller fish at the head end of the compartment, the area behind the fish can be filled with soft synthetic foam. The length of the compartment, however, seems to be less critical than its width. Most fish remain at the head end possibly as a result of the shape of the compartment and the electrical shock stimulation across the caudal half of the body. If the fish fits too loosely between the membranous walls, it may struggle persistently, and such movements impair detection of the respiratory beat. The incidence of thrashing sometimes declines in successive sessions. Administration of the unconditioned electric shock stimulus between trials can inhibit thrashing and erratic breathing movements as well. Swimming movements can be physically impeded by placing a thin wedge of soft foam over the tail. Firm compression of the tail is avoided for the reasons mentioned above.

\section{REFERENCES}

Davis, R. E., \& Benloucif, S. Behavioral investigation of neurotoxicity: The effects of colchicine, lumicolchicine and vincristine sulfate on goldfish optic nerve regeneration. Neurotoxicology, in press.

Overmier, J. B., \& Curnow, P. F. Classical conditioning, pseudoconditioning, and sensitization in "normal" and forebrainless goldfish. Journal of Comparative and Physiological Psychology, 1969, 68, 193-198.

Overmier, J. B., \& Savage, G. E. Effects of telencephalic ablation on trace classical conditioning of heart rate in goldfish. Experimental Neurology, 1974, 42, 339-346.

Powers, M. K., \& EAster, S. S. Behavioral confirmation of the "silent period" during adaptation to bright lights. Vision Research, 1978, 18, 1075-1077.

Northmore, D. P. M., \& Yager, D. Psychophysical methods for investigations of vision in fishes. In M. A. Ali (Ed.), Vision in fishes. New York: Plenum, 1975.

Yager, D., \& Sharma, S. C. Evidence for visual function mediated by anomalous projection in goldfish. Nature, 1975, 256, 490-491.

(Received for publication August 8, 1981; accepted August 9, 1981.) 